Federal Reserve Bank of Minneapolis

Research Department

\title{
A Simple Model of Bank Employee Compensation*
}

\author{
Christopher Phelan
}

Working Paper 676

December 2009

*Phelan: University of Minnesota and Federal Reserve Bank of Minneapolis. This is a very preliminary working paper, with no citations or bibliography, and no acknowledgment of the vast amount of previous work in related subjects. It is posted now to provide those interested in the underlying model behind the accompanying paper, "Incentive Compensation in the Banking Industry: Insights from Economic Theory," which I coauthored with Douglas Clement. For these omissions, I apologize. A proper revision addressing these debts will be posted when ready. The views expressed herein are those of the author and not necessarily those of the Federal Reserve Bank of Minneapolis or the Federal Reserve System. 


\section{Introduction}

This paper considers the question, Does the limited liability associated with banking make it necessary for a government to regulate bank employee compensation? It attempts to shed light on this question by considering a mechanism design framework. In it, a single riskaverse employee must be induced to search for good investment opportunities and turn down bad investment opportunities. The paper considers various environments determining who chooses this employee's compensation scheme: (1) a social planner; (2) shareholders with limited liability and nonguaranteed debt; (3) shareholders with limited liability and government guaranteed debt, but where the government charges an appropriate risk-based insurance premium; and (4) shareholders with limited liability, government guaranteed debt, and a fixed or nonexistent insurance premium. In the first case, where the employee's compensation plan is chosen by a social planner, we derive and characterize the efficient compensation scheme for the employee. We then show that the shareholders will choose this efficient compensation scheme in all but the last scenario.

\section{The Model}

Consider a bank employee who must choose whether to invest in a risky project which $\operatorname{costs} x$ or to park $x$ in a riskless asset. Let project $i$ be a joint probability distribution $\Pi_{i}\left(y_{1}, y_{2}\right)$ over outcomes $y_{1}$ (the return of the project in period $t=1$ ) and $y_{2}$ (the return of the project in period $t=2$ ). Let $I$ be the set of projects and assume $I=\{A, B\}$, where $A$ is a "good" risky project with a mean return better than the riskless asset and $B$ is a "bad" risky project with a mean return worse than the riskless asset.

At the beginning of the first period, the employee privately chooses whether to search 
for a risky project. If he chooses not to search, his only option is to invest $x$ in the riskless project which returns $R$ per period. If he chooses to search for a risky project, then he draws project $i \in I$ according to the probability distribution $P_{i}$. Whether he invests in the riskless or risky asset is publicly observable, but which asset $i$ he drew from the risky asset pool, or whether he drew from the risky project pool at all, is known only to the employee.

Assume that the employee has utility for per period consumption $u(c)$ (where $u$ is strictly concave) and gets disutility $d$ from searching for a risky project. Also assume that the bank is risk-neutral, the employee's discount parameter is $\beta<1$, the employee has some lifetime outside utility possibility $U$, and the bank's rate of return $R=1 / \beta$. Further assume that parameters are such that it is efficient for the employee to search for a risky project, invest in the risky project if project $A$ is drawn, and invest in the riskless asset if project $B$ is drawn.

\section{Social Optimum}

An employment contract in this environment is a pair of scalars $c_{1}^{0} \geq 0$ and $c_{2}^{0} \geq 0$ representing the employee's consumption in each period if he chooses to invest in the riskless asset, as well as functions $c_{1}\left(y_{1}\right) \geq 0$ and $c_{2}\left(y_{1}, y_{2}\right) \geq 0$, representing his consumption in each period if he invests in a risky project and it returns $y_{1}$ in period 1 and $y_{2}$ in period 2. A contract $\left(c_{1}^{0}, c_{2}^{0}, c_{1}\left(y_{1}\right), c_{2}\left(y_{1}, y_{2}\right)\right)$ is said to be incentive compatible if two incentive compatibility conditions hold. The first condition is that the employee must be willing to search for a risky project rather than simply announcing he drew project $B$, thus avoiding 
the search cost $d$, or

$$
\begin{aligned}
& P_{A} \sum_{y_{1}, y_{2}} \Pi_{A}\left(y_{1}, y_{2}\right)\left[u\left(c_{1}\left(y_{1}\right)\right)+\beta u\left(c_{2}\left(y_{1}, y_{2}\right)\right)\right]+P_{B}\left[u\left(c_{1}^{0}\right)+\beta u\left(c_{2}^{0}\right)\right]-d \\
\geq & u\left(c_{1}^{0}\right)+\beta u\left(c_{2}^{0}\right) .
\end{aligned}
$$

The second condition is that if project $B$ is drawn, the employee must prefer investing in the riskless asset to investing in project $B$, or

$$
u\left(c_{1}^{0}\right)+\beta u\left(c_{2}^{0}\right) \geq \sum_{y_{1}, y_{2}} \Pi_{B}\left(y_{1}, y_{2}\right)\left[u\left(c_{1}\left(y_{1}\right)\right)+\beta u\left(c_{2}\left(y_{1}, y_{2}\right)\right)\right]
$$

One does not need a condition ensuring that the employee choose project $A$ if drawn, rather than invest in the riskless asset. Equation (1) and $d \geq 0$ imply that

$$
\sum_{y_{1}, y_{2}} \Pi_{A}\left(y_{1}, y_{2}\right)\left[u\left(c_{1}\left(y_{1}\right)\right)+\beta u\left(c_{2}\left(y_{1}, y_{2}\right)\right)\right] \geq u\left(c_{1}^{0}\right)+\beta u\left(c_{2}^{0}\right)
$$

We say that an employment contract is incentive feasible if it is incentive compatible and delivers to the employee an expected discounted stream of utilities of at least $U$, or

$$
P_{A} \sum_{y_{1}, y_{2}} \Pi_{A}\left(y_{1}, y_{2}\right)\left[u\left(c_{1}\left(y_{1}\right)\right)+\beta u\left(c_{2}\left(y_{1}, y_{2}\right)\right)\right]+P_{B}\left[u\left(c_{1}^{0}\right)+\beta u\left(c_{2}^{0}\right)\right]-d \geq U
$$

Let the surplus associated with an employment contract $\left(c_{1}^{0}, c_{2}^{0}, c_{1}\left(y_{1}\right), c_{2}\left(y_{1}, y_{2}\right)\right)$ be the expected discounted returns of the project over and above the consumption of the employee, 
or

$$
\begin{aligned}
S\left(c_{1}^{0}, c_{2}^{0}, c_{1}\left(y_{1}\right), c_{2}\left(y_{1}, y_{2}\right)\right) & =P_{A} \sum_{y_{1}, y_{2}} \Pi_{A}\left(y_{1}, y_{2}\right)\left[y_{1}+\frac{1}{R} y_{2}-c_{1}\left(y_{1}\right)-\frac{1}{R} c_{2}\left(y_{1}, y_{2}\right)\right] \\
& +P_{B}\left[x-c_{1}^{0}-\frac{1}{R} c_{2}^{0}\right] .
\end{aligned}
$$

We say a contract is efficient if all other incentive feasible contracts have a weakly lower surplus.

\section{A. Characterization}

If $d=0$, or searching for a risky project costs the employee nothing, the problem of maximizing surplus subject to incentive feasibility has a simple solution: a constant wage $\left(c_{1}^{0}=c_{2}^{0}=c_{1}\left(y_{1}\right)=c_{2}\left(y_{1}, y_{2}\right)\right.$ for all $\left.\left(y_{1}, y_{2}\right)\right)$. That is, the employee's consumption is constant over time, constant over whether the employee chooses the risky project or the riskless asset, and constant over the outcome of the risky project if chosen. The constant over time result comes from equal discounting $(\beta=1 / R)$. The result that the employee's consumption is the same regardless of whether he chooses the riskless asset or a risky project, and the same regardless of the outcome of the risky project (if the risky project is chosen), comes from the fact that a constant wage is incentive compatible. Put in words, if inducing the employee to search for a good risky project is not an issue, a constant wage gives the employee no motive to disobey his instructions regarding which project to fund and which to turn down.

If $d>0$, this problem now has a more interesting solution. Now a constant wage is not incentive compatible because the first incentive constraint (1) is violated. The employee is better off not searching and simply investing in the riskless asset. So perhaps then the 
employee should face a constant $c_{1}\left(y_{1}\right)$ and constant $c_{2}\left(y_{1}, y_{2}\right)$ (over outcomes $\left(y_{1}, y_{2}\right)$ ), but the constant $c_{1}\left(y_{1}\right)$ should exceed $c_{1}^{0}$ and/or the constant $c_{2}\left(y_{1}, y_{2}\right)$ should exceed $c_{2}^{0}$. That is, the employee should still be insured against variations in the outcome of the risky project (if funded) but should be paid a premium for funding the risky project. But this solution is also not incentive compatible because it violates (2). In words, if the employee receives a constant higher utility when funding the risky project versus a constant lower utility when not, and this difference is high enough to induce him to search for a risky project, then if he draws project $B$, he will choose to fund regardless. Thus, $c_{1}\left(y_{1}\right)$ or $c_{2}\left(y_{1}, y_{2}\right)$ must be nontrivial functions of $y_{1}$ and $y_{2}$.

Next, note that if $d>0$, then equation (1) implies that

$$
\sum_{y_{1}, y_{2}} \Pi_{A}\left(y_{1}, y_{2}\right)\left[u\left(c_{1}\left(y_{1}\right)\right)+\beta u\left(c_{2}\left(y_{1}, y_{2}\right)\right)\right]>u\left(c_{1}^{0}\right)+\beta u\left(c_{2}^{0}\right) .
$$

In words, the expected utility of the employee who draws project $A$ (the left-hand side of the previous equation) strictly exceeds the certain utility of the employee if he draws project $B$. Since $u$ is concave, this implies that the expected present value of consumption of the employee who draws project $A$ strictly exceeds the certain present value of consumption of the employee if he draws project $B$.

Next, consider the first-order condition with respect to $c_{2}\left(y_{1}, y_{2}\right)$. If $\lambda$ is the multiplier on the participation constraint (4), $\alpha$ is the multiplier on the "willingness to search for a risky project" constraint (1), and $\gamma$ is the multiplier on the "willingness not to fund project 
B" constraint (2), then, with a little manipulation, this first-order condition becomes

(7) $1=\left[\lambda+\alpha-\frac{\gamma}{P_{A}} \frac{\Pi_{B}\left(y_{1}, y_{2}\right)}{\Pi_{A}\left(y_{1}, y_{2}\right)}\right] u^{\prime}\left(c_{2}\left(y_{1}, y_{2}\right)\right)$.

That is, increasing $c_{2}\left(y_{1}, y_{2}\right)$ is a matter of balancing how doing this lowers the contract's surplus (the 1 on the left-hand side) against how it loosens the participation constraint (the $\lambda u^{\prime}\left(c_{2}\left(y_{1}, y_{2}\right)\right)$ on the right-hand side), how it loosens the "willingness to search" constraint (the $\alpha u^{\prime}\left(c_{2}\left(y_{1}, y_{2}\right)\right)$ on the right-hand side), and how it tightens the constraint associated with getting the employee to be willing not to fund project $B$. (Increasing $c_{2}\left(y_{1}, y_{2}\right)$ always tightens this last constraint, since $c_{2}\left(y_{1}, y_{2}\right)$ is conditional on the employee funding the risky project, but especially tightens it for those $\left(y_{1}, y_{2}\right)$ outcomes which are relatively more likely given project $B$ than project $A$.) Thus, not surprisingly, an efficient contract will tend to punish, with relatively low $c_{2}\left(y_{1}, y_{2}\right)$, outcomes more likely to occur under project $B$ than project $A$, and reward, with relatively high $c_{2}\left(y_{1}, y_{2}\right)$, outcomes more likely to occur under project $A$ than project $B$.

\section{B. Intertemporal Properties}

If one considers the first-order condition with respect to $c_{1}\left(y_{1}\right)$, the same simplification delivers

(8) $1=\left[\lambda+\alpha-\frac{\gamma}{P_{A}} \frac{\Pi_{B}\left(y_{1}\right)}{\Pi_{A}\left(y_{1}\right)}\right] u^{\prime}\left(c_{1}\left(y_{1}\right)\right)$, 
where $\Pi_{i}\left(y_{1}\right)=\sum_{y_{2}} \Pi_{i}\left(y_{1}, y_{2}\right)$. Thus, from (7) we have

(9) $\frac{1}{u^{\prime}\left(c_{2}\left(y_{1}, y_{2}\right)\right)}=\lambda+\alpha-\frac{\gamma}{P_{A}} \frac{\Pi_{B}\left(y_{1}, y_{2}\right)}{\Pi_{A}\left(y_{1}, y_{2}\right)}$

and from (8) we have

(10) $\frac{1}{u^{\prime}\left(c_{1}\left(y_{1}\right)\right)}=\lambda+\alpha-\frac{\gamma}{P_{A}} \frac{\Pi_{B}\left(y_{1}\right)}{\Pi_{A}\left(y_{1}\right)}$.

If one then takes the expected value of equations (9) and (10), one has

$$
\sum_{y_{1}, y_{2}} \Pi_{A}\left(y_{1}, y_{2}\right) \frac{1}{u^{\prime}\left(c_{2}\left(y_{1}, y_{2}\right)\right)}=\lambda+\alpha-\frac{\gamma}{P_{A}}
$$

and

$$
\sum_{y_{1}} \Pi_{A}\left(y_{1}\right) \frac{1}{u^{\prime}\left(c_{1}\left(y_{1}\right)\right)}=\lambda+\alpha-\frac{\gamma}{P_{A}}
$$

or that the expected value of $1 / u^{\prime}(c)$ is constant over time.

$$
\text { If } u(c)=\log (c) \text {, then } 1 / u^{\prime}(c)=c \text {, in which case the expected consumption of the }
$$
employee, conditional on funding the project, is the same in periods 1 and 2 , regardless of the properties of $\Pi_{A}$ and $\Pi_{B}$. That in period 2, more is known about the outcome of the project than in period 1 is irrelevant.

Suppose instead that $u(c)=c^{\alpha} / \alpha$, where, as usual, $\alpha=0$ is represented as $u(c)=$ $\log (c), 0<\alpha<1$ implies less curvature than $\log$ and $\alpha<0$ implies more curvature than log, and consider an extreme example of $\Pi_{A}$ and $\Pi_{B}$. That is, suppose $\Pi_{A}\left(y_{1}\right)=\Pi_{B}\left(y_{1}\right)$ for all $y_{1}$, or that all information regarding whether the employee chose project $A$ or $B$ comes 
in the second period. Then, from (10), $c_{1}\left(y_{1}\right)$ is the same for all $y_{1}$, whereas $c_{2}\left(y_{1}, y_{2}\right)$ must depend on $y_{2}$ (or else projects $A$ and $B$ do not differ). Now, if $\alpha>0,1 / u^{\prime}(c)$ is a concave function and if $\alpha<0,1 / u^{\prime}(c)$ is a convex function. In the first case $(\alpha>0)$, expected consumption will be higher in period 2 than in period 1 , whereas in the second case $(\alpha<0)$, expected consumption will be lower in period 2 than in period 1, even though, by assumption, all information about the project is revealed in period 2.

\section{Banking}

Now consider a bank with a single employee facing the same problem as in the previous section. Further assume that the bank has assets $a<x$; thus, it needs to raise funds if the employee is to invest in the risky asset. Also assume that $a>(1+\beta) \bar{c}$, where $\bar{c}$ solves $U=(1+\beta) u(\bar{c})$. This assumption implies that the bank is solvent, or can afford to pay its employee a contract giving utility $U$.

Further suppose that funds $x-a$ must be raised in the form of nonguaranteed debt. That is, for given compensation functions $c_{1}\left(y_{1}\right)$ and $c_{2}\left(y_{1}, y_{2}\right)$, if the risky project is chosen and has realization $\left(y_{1}, y_{2}\right)$, the bank's "cash on hand" at the end of period 2 is $y_{1} R+y_{2}-$ $c_{1}\left(y_{1}\right) R-c_{2}\left(y_{1}, y_{2}\right)$. A debt contract is then a promise by the bank to pay an amount $D$ when $D \leq y_{1} R+y_{2}-c_{1}\left(y_{1}\right) R-c_{2}\left(y_{1}, y_{2}\right)$ and $y_{1} R+y_{2}-c_{1}\left(y_{1}\right) R-c_{2}\left(y_{1}, y_{2}\right)$ otherwise. (If the riskless project is chosen, the bank is assumed not to raise any funds.)

We assume, however, that the bank can raise $x-a$ only if in expectation the debt contract pays $(x-a) R$, or

$$
\sum_{y_{1}, y_{2}} \Pi_{A}\left(y_{1}, y_{2}\right) \min \left\{D, y_{1} R+y_{2}-c_{1}\left(y_{1}\right) R-c_{2}\left(y_{1}, y_{2}\right)\right\} \geq(x-a) R .
$$


The problem for the bank's shareholders can then be expressed as

$$
\begin{gathered}
\max _{D, c_{1}^{0}, c_{2}^{0}, c_{1}\left(y_{1}\right), c_{2}\left(y_{1}, y_{2}\right)} P_{B}\left[a-c_{1}^{0}-\frac{1}{R} c_{2}^{0}\right]+ \\
P_{A} \sum_{y_{1}, y_{2}} \Pi_{A}\left(y_{1}, y_{2}\right) \frac{1}{R} \max \left(0, y_{1} R+y_{2}-c_{1}\left(y_{1}\right) R-c_{2}\left(y_{1}, y_{2}\right)-D\right)
\end{gathered}
$$

subject to incentive feasibility (equations (1), (2), and (4)) as well as (13).

The main result of this section is that this program has the same solution as the social optimum. To see this, first note that the first-order conditions with respect to $c_{1}^{0}$ and $c_{2}^{0}$ are identical. Next, consider the first-order condition with respect to $c_{2}\left(y_{1}, y_{2}\right)$ (for a given $\left.\left(y_{1}, y_{2}\right)\right)$. If $\left(y_{1}, y_{2}\right)$ are such that $y_{1} R+y_{2} \geq c_{1}\left(y_{1}\right) R+c_{2}\left(y_{1}, y_{2}\right)+D$, then this first-order condition is unchanged (or equal to equation (7)). If $\left(y_{1}, y_{2}\right)$ are such that $y_{1} R+y_{2}<$ $c_{1}\left(y_{1}\right) R+c_{2}\left(y_{1}, y_{2}\right)+D$, then this first-order condition becomes

$$
\frac{R}{P_{A}} \xi=\left[\lambda+\alpha-\frac{\gamma}{P_{A}} \frac{\Pi_{B}\left(y_{1}, y_{2}\right)}{\Pi_{A}\left(y_{1}, y_{2}\right)}\right] u^{\prime}\left(c_{2}\left(y_{1}, y_{2}\right)\right)
$$

where $\xi$ is the Lagrange multiplier on (13).

Next, consider the first-order condition with respect to $c_{1}\left(y_{1}\right)$. This becomes

$$
\operatorname{Prob}\left(\text { solvent } \mid y_{1}\right)+\frac{R}{P_{A}} \xi\left(1-\operatorname{Prob}\left(\text { solvent } \mid y_{1}\right)\right)=\left[\lambda+\alpha-\frac{\gamma}{P_{A}} \frac{\Pi_{B}\left(y_{1}\right)}{\Pi_{A}\left(y_{1}\right)}\right] u^{\prime}\left(c_{1}\left(y_{1}\right)\right)
$$

where

$$
\operatorname{Prob}\left(\text { solvent } \mid y_{1}\right)=\frac{\sum_{y_{2} \mid D \leq y_{1} R+y_{2}-c_{1}\left(y_{1}\right) R-c_{2}\left(y_{1}, y_{2}\right)} \Pi_{A}\left(y_{1}, y_{2}\right)}{\sum_{y_{2}} \Pi_{A}\left(y_{1}, y_{2}\right)}
$$

Now set $c_{1}^{0}, c_{2}^{0}, c_{1}\left(y_{1}\right), c_{2}\left(y_{1}, y_{2}\right), \lambda, \mu$, and $\gamma$ equal to their values in the solution to 
the social optimum problem of the previous section, and let $\xi=\frac{P_{A}}{R}$. Then equations (15) and (16) hold. Setting $D$ such that (13) holds with equality then solves the shareholder's problem, implying that shareholders will choose the socially efficient compensation scheme.

\section{Guaranteed Debt with Risk-Based Premiums}

Consider a bank in the same situation as in the previous section, but suppose that funds $x-a$ must be raised in the form of government guaranteed debt. (As before, if the riskless project is chosen, the bank is assumed not to raise any funds.) Since debt holders receive the payment $D$ from either the bank or the government with certainty, we can assume that $D=(x-a) R$.

Next, suppose that the government charges a premium to the bank for their insurance, $I$, as a function of $c_{1}\left(y_{1}\right)$ and $c_{2}\left(y_{2}\right)$. In particular, assume that if $y_{1} R+y_{2} \geq c_{1}\left(y_{1}\right) R+$ $c_{2}\left(y_{1}, y_{2}\right)+(x-a) R+I$, then the bank pays the entire premium, $I$, and the shareholders receive $y_{1} R+y_{2}-\left(c_{1}\left(y_{1}\right) R+c_{2}\left(y_{1}, y_{2}\right)+(x-a) R+I\right)$. If $c_{1}\left(y_{1}\right) R+c_{2}\left(y_{1}, y_{2}\right)+(x-a) R<$ $y_{1} R+y_{2}<c_{1}\left(y_{1}\right) R+c_{2}\left(y_{1}, y_{2}\right)+(x-a) R+I$ (or the bank can afford to pay its employee and its debt holders but not its insurance premium), then the shareholders receive nothing, the government pays the debt holders nothing, and the government receives a partial insurance payment $y_{1} R+y_{2}-\left(c_{1}\left(y_{1}\right) R+c_{2}\left(y_{1}, y_{2}\right)+(x-a) R\right)$. Finally, if $y_{1} R+y_{2}<c_{1}\left(y_{1}\right) R+$ $c_{2}\left(y_{1}, y_{2}\right)+(x-a) R$, then shareholders receive nothing and the government pays debt holders $(x-a) R-\left(y_{1} R+y_{2}-c_{1}\left(y_{1}\right) R-c_{2}\left(y_{1}, y_{2}\right)\right)$.

Assume that premium $I$ is such that, in expectation, the government breaks even, or

$$
\sum_{y_{1}, y_{2}} \Pi_{A}\left(y_{1}, y_{2}\right) \min \left\{I, y_{1} R+y_{2}-c_{1}\left(y_{1}\right) R-c_{2}\left(y_{1}, y_{2}\right)-(x-a) R\right\} \geq 0
$$


In this case, the appropriate maximization problem for the bank shareholders becomes

$$
\begin{aligned}
& \max _{c_{1}^{0}, c_{2}^{0}, c_{1}\left(y_{1}\right), c_{2}\left(y_{1}, y_{2}\right)} P_{B}\left[a-c_{1}^{0}-\frac{1}{R} c_{2}^{0}\right]+ \\
& P_{A} \sum_{y_{1}, y_{2}} \Pi_{A}\left(y_{1}, y_{2}\right) \frac{1}{R} \max \left(0, y_{1} R+y_{2}-c_{1}\left(y_{1}\right) R-c_{2}\left(y_{1}, y_{2}\right)-(x-a) R-I\right)
\end{aligned}
$$

subject to incentive feasibility (equations (1), (2), and (4)) as well as (18).

The main point of this section is that this optimization problem is exactly the same as the one considered in the previous section with uninsured banks. That is, take equation (13) and subtract $(x-a) R$ from each side, yielding

$$
\sum_{y_{1}, y_{2}} \Pi_{A}\left(y_{1}, y_{2}\right) \min \left\{D-(x-a) R, y_{1} R+y_{2}-c_{1}\left(y_{1}\right) R-c_{2}\left(y_{1}, y_{2}\right)-(x-a) R\right\} \geq 0 .
$$

Next, with guaranteed debt, the total amount $D$ that banks must pay out if they do not default is $(x-a) R+I$. Substituting $(x-a) R+I$ for $D$ then delivers equation (18).

Thus, if the government charges an insurance premium such that for all compensation plans, the expected cost of providing this insurance to the bank is zero, the bank is again induced to provide the efficient employment compensation scheme, even in the presence of guaranteed debt.

\section{Guaranteed Debt without Risk-Based Premiums}

Finally, consider the shareholder's problem with $I=0$ ( $I$ equal to any fixed number is equivalent) and no requirement that the government, in expectation, break even in its guarantee of debt. The shareholder's optimization problem is then exactly that in (19) with $I=0$ and without (18) as a constraint. 
Our first observation is that this is no longer a well-behaved optimization problem. In particular, consider the first-order condition with respect to $c_{2}\left(y_{1}, y_{2}\right)$. If $y_{1} R+y_{2}>$ $c_{1}\left(y_{1}\right) R+c_{2}\left(y_{1}, y_{2}\right)+(x-a) R$ (or the bank can pay its debt $D$ even if it marginally increases $\left.c_{2}\left(y_{1}, y_{2}\right)\right)$, then this condition is unchanged from equation (7). However, if $y_{1} R+y_{2} \leq$ $c_{1}\left(y_{1}\right) R+c_{2}\left(y_{1}, y_{2}\right)+(x-a) R$ (or marginally increasing $c_{2}\left(y_{1}, y_{2}\right)$ takes from the government rather than the shareholders), then this first-order condition becomes

$$
0=\left[\lambda+\alpha-\frac{\gamma}{P_{A}} \frac{\Pi_{B}\left(y_{1}, y_{2}\right)}{\Pi_{A}\left(y_{1}, y_{2}\right)}\right] u^{\prime}\left(c_{2}\left(y_{1}, y_{2}\right)\right)
$$

where the only difference between (7) and (21) is that the left-hand side, the cost to the objective function of marginally increasing $c_{2}\left(y_{1}, y_{2}\right)$, is zero instead of one. But note that since $u^{\prime}(c)>0$ for all $c$, this equation, generically, cannot hold. Thus, in order for this case to be a well-behaved optimization problem, one would have to impose an upper bound on the employee's consumption in default states, and further, optimization by the shareholders would imply that $c_{2}\left(y_{1}, y_{2}\right)$ would hit this upper bound in all default states (or states where $\left.y_{1} R+y_{2}<c_{1}\left(y_{1}\right) R+c_{2}\left(y_{1}, y_{2}\right)+(x-a) R\right)$.

In essence, if contractual obligations to the employee take precedence over government guaranteed debt, then shareholders with no altruism toward the employee whatsoever will nevertheless choose to structure the employment contract to pay the employee as much as possible in default states. Doing so gets the government to subsidize the bank's wage bill.

Perhaps more interestingly, however, guaranteed debt also has implications on firstperiod pay. Consider the first-order condition with respect to $c_{1}\left(y_{1}\right)$. Recall that without 
debt, this first-order condition (simplified) was

(22) $1=\left[\lambda+\alpha-\frac{\gamma}{P_{A}} \frac{\Pi_{B}\left(y_{1}\right)}{\Pi_{A}\left(y_{1}\right)}\right] u^{\prime}\left(c_{1}\left(y_{1}\right)\right)$

where, again, the 1 on the left-hand side is the cost to the objective function, the shareholder's expected returns, of increasing $c_{1}\left(y_{1}\right)$. With debt, this first-order condition becomes

$$
\operatorname{Prob}\left(\text { Solvent } \mid y_{1}\right)=\left[\lambda+\alpha-\frac{\gamma}{P_{A}} \frac{\Pi_{B}\left(y_{1}\right)}{\Pi_{A}\left(y_{1}\right)}\right] u^{\prime}\left(c_{1}\left(y_{1}\right)\right)
$$

The right-hand side of (23) (the effect of marginally increasing $c_{1}\left(y_{1}\right)$ on the constraints) is unchanged, but the left-hand side, the cost to the shareholders, instead of unity, becomes the probability that $y_{2}$ will be such that the marginal wage dollar is paid by the shareholders as opposed to the government. That is, marginally increasing $c_{2}\left(y_{1}\right)$ does not increase the cost to the shareholders if $y_{2}$ turns out to be such that the bank defaults. In that case, with or without increasing $c_{1}\left(y_{1}\right)$, the shareholders receive nothing. Thus, the shareholders have an incentive to increase first-period consumption in precisely those $y_{1}$ realizations for which the probability of default in the following period is high. Again, this is not because the shareholders in some way prefer the employee to the government. It is a simple matter of getting the government to pay part of the bank's wage bill.

\section{Policy Recommendations}

A drawback of the mechanism design approach is that in some simple sense, the optimal regulation here is to force banks to set $c_{0}^{1}, c_{0}^{2}, c_{1}\left(y_{1}\right)$, and $c_{2}\left(y_{1}, y_{2}\right)$ equal to those 
values which solve the programming problem associated with the social optimum. But such a recommendation, of course, cannot be taken seriously. Nothing in this analysis considers the fact that the regulator has less information regarding the problem facing the bank than the bank itself, nor does such a policy recommendation recognize that the entire exercise is a stark simplification of the actual issues facing banks, bank employees, and regulators. But noting that the real world is more complicated than the model here does provide some insight regarding policy.

This idea that the regulator should somehow get shareholders to choose the compensation schemes they would have chosen if were not for government debt guarantees is a general one. The idea would survive no matter how complicated or realistic the model. What is problematic is the idea that regulators can somehow divine what this efficient compensation scheme would be. But it is this very idea - that regulators can figure out the efficient compensation scheme - that underlies regulators directly regulating employee compensation schemes.

In the policy prescription outlined in Section 5, "Guaranteed Debt with Risk-Based Premiums," no such direct regulation of employee compensation schemes is needed. Instead, regulators would allow shareholders to compensate their employees in any way they chose, but would design their insurance premiums such that, in expectation, for every compensation scheme, the government would break even. Is it any easier for a regulator to design such an optimal premium structure versus directly regulating employee compensation? Here, markets can help overcome this difficulty.

In particular, assume the government insures only, say, $99 \%$ of bank debt and requires the shareholders to buy private insurance for the other $1 \%$. If one is worried about these 
private insurers themselves going bankrupt, the insurers could be required to post a bond with the regulator equal to $100 \%$ of the insured amount. Such a requirement would add only $1 \%$ to total reserve requirements. But if the government also requires the shareholders to pay 99 times the amount they paid for the private insurance to the government, since the private insurers are presumably, in expectation, breaking even, so would the government. Thus, equation (18) is satisfied, and the result of Section 5 applies - the shareholders will voluntarily choose the efficient compensation scheme. 